\title{
$\begin{array}{ll}\text { Research Square } & \text { Preprints are preliminary reports that have not undergone peer review. } \\ \text { They should not be considered conclusive, used to inform clinical practice, }\end{array}$ or referenced by the media as validated information. \\ LncRNA RP11-59J16.2 Aggravates Apoptosis and Increases Tau Phosphorylation via Inhibiting MCM2 On The AD SH-SY5Y Cell Model Induced By A $\beta$.
}

\section{Fulin Guan}

First Affiliated Hospital of Harbin Medical University

\section{Qichang Gao}

First Affiliated Hospital of Harbin Medical University

Jiaao Gu

First Affiliated Hospital of Harbin Medical University

\section{Xinghua Dai}

Haiyuan Hospital of Heilongjiang

Lei Li (D 420944293@qq.com )

First Affiliated Hospital of Harbin Medical University

\section{Rui Bao}

Heilongjiang University of Chinese Medicine

\section{Research}

Keywords: Alzheimer disease, microarray analysis, RP11-59J16.2, MCM2, apoptosis, p-Tau

Posted Date: November 11th, 2021

DOI: https://doi.org/10.21203/rs.3.rs-1031757/v1

License: (9) (i) This work is licensed under a Creative Commons Attribution 4.0 International License. Read Full License 


\section{Abstract}

\section{Objective}

Alzheimer's disease (AD) is a degenerative disease of central nervous system with unclear pathogenesis, accounting for $60 \%-70 \%$ of dementia cases. It is necessary to study the pathogenesis and therapeutic prospect of $A D$. LncRNAs have been found to play an important role in the development of AD. This study aims to explore the role of differentially expressed IncRNAs in AD patients' serum in the pathogenesis of AD.

\section{Methods}

In this study, serum microarray analysis was performed in AD patients and healthy controls to establish IncRNAs and mRNA expression profiles. The biological processes and key pathways were identified by GO analysis and KEGG pathway analysis. A protein-protein interaction network was analyzed and constructed by using String database. SH-SY5Y cells were treated with AB 1-42 to establish AD cell model. The expression of RP11-59J16.2 and MCM2 was detected by qRT-PCR. The mRNA binding sites and target genes of RP11-59J16.2 were predicted by bioinformatics analysis. Dual luciferase reporter gene analysis verified the targeting effect of RP11-59J16.2 on MCM2. Inhibition of RP11-59J16.2 or overexpression of MCM2, CCK-8 and flow cytometry were used to detect cell viability and apoptosis and Western Blot was used to detect the expression of $\mathrm{p}$-Tau.

\section{Results}

Differential expression of IncRNAs and mRNAs was screened by microarray data, and high expression of RP11-59J16.2 and low expression of MCM2 were detected in serum of AD patients. GO analysis and KEGG pathway analysis revealed that $\mathrm{G}_{1} / \mathrm{S}$ transition of mitotic cell cycle may be involved in the development of AD. The mRNA binding sites and target genes of RP11-59J16.2 were predicted by bioinformatics analysis. Dual luciferase reporter gene analysis, qRT-PCR and Western Blot were used to verify the targeted regulation of RP11-59J16.2 on MCM2. The expression of RP11-59J16.2 was increased and that of MCM2 was decreased in SH-SY5Y cells treated with AB1-42. CCK-8 assay and Annexin V FITC/PI apoptosis assay kit results showed that RP11-59J16.2 could reduce cell viability, aggravate apoptosis and increase Tau phosphorylation in AD cell model by inhibiting MCM2.

\section{Conclusion}

Through gene microarray and bioinformatics analysis, high differentially expressed IncRNAs RP1159J16.2 and low expressed mRNA MCM2 in AD patients were screened. By using bioinformatics prediction and dual luciferase reporter gene analysis, it was confirmed that RP11-59J16.2 could target MCM2 regulation. SH-SY5Y cells were treated with $A \beta 1-42$ to construct $A D$ cell model. Overexpression or inhibition of RP11-59J16.2 or MCM2, we found that RP11-59J16.2 could promote neuronal apoptosis 
and increase Tau phosphorylation by regulating MCM2 in vitro. Thus, RP11-59J16.2 might be a potential target molecule for the prediction, diagnosis and treatment of $A D$.

\section{Introduction}

Alzheimer's disease (AD) is most common cause of dementia in aging population. Involved with a complex neurodegenerative pathogenesis, the accumulation of $\beta$-amyloid and intracellular neurofibrillary tangles are the main pathological hallmarks of $A D[1]$. The prevalence of $A D$ was closely related to age, it was doubled for every 6.1 -years-old and it could be as high as $20-30 \%$ in the people over 85 years old. By 2050, there will be more than 100 million AD patients over the world[2]. AD is life-threatening and constitutes a considerable portion of the medical and care burden to families and society. Due to the unclear etiology and complex pathogenesis, none of the current $A D$ drugs can reverse the disease process[3]. Therefore, it is important to study the potential mechanism of AD occurrence and development.

It was reported that non-coding RNA (ncRNA) such as IncRNA and microRNA plays an important role in cell survival[ $[4,5]$. Long non-coding RNAs (IncRNAs) are non-coding RNAs with more than 200 nucleotide sequences. Their regulatory role in tumors has been explored worldwide[6, 7]. LncRNAs can regulate cell progression through targeting miRNAs or mRNA[8,9]. More and more evidence shows that IncRNAs can be used as important molecular markers involved in gene regulation and cell progression[10]. Minichromosome maintenance complex component 2 (MCM2) gene is a major gene affecting the stability of

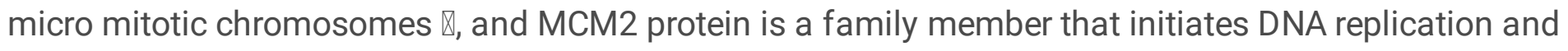
maintains progression in the cell cycle[11]. Human MCM2 was first reported in 1998[12]. MCM2 is located on chromosome 3q21.3 and comprises 17 exons[13]. According to recent reports[14], MCM2 was verified as a cell marker of cell proliferation which indicated that MCM2 could repair neuronal injury in AD through promoting neuronal injury. Previous study[15] showed that phosphorylated MCM2 was strikingly associated with the characteristic NFT in AD and its localization in the cytoplasm of neurons suggests its effect on resultant cell cycle stasis and consequent neuronal degeneration.

We studied the expression profiles of IncRNAs and mRNAs in serum of AD patients, and found that the expression of RP11-59J16.2 and MCM2 in AD patients has significant differences compared with healthy control. However, the role of RP11-59J16.2/MCM2 in the development of AD was unclear. In this study, the effect of RP11-59J16.2/MCM2 on the development of AD would be investigated to explore the molecular mechanism of RP11-59J16.2 on regulation of A -induced neuronal damage in the AD cell model by targeting MCM2, and to provide a potential target and theoretical basis for the treatment of AD.

\section{Materials And Methods}

\section{Ethics Statement}


The patients included in the present study provided written informed consent. The study was approved by the ethics committee of Harbin Medical University.

\section{Sample collection}

$A D$ patients aged 65-75 who met the diagnostic criteria for AD were selected from Neurology Department in the first affiliated hospital of Harbin Medical University. Peripheral blood samples of AD patients and healthy control with the same age group were collected. Inclusion criteria for AD patients were as follows.

For the AD patients: (1) Participants aged 65-75 years were recruited; (2) It conforms to the National Institute of Neurological and Communicative Disorders and Stroke/Alzheimer's disease Criteria (NINCDSADRDA) for diagnosis of probable Alzheimer disease; (3) Subjects or their caregivers voluntarily participate in the study and sign the informed consent. Subjects were excluded if they had a history of head trauma. Exclusion criteria: (1) Age <65 years. (2) Other dementia or other genetic history in the family. (3) Patients with significant depressive symptoms with Hamilton Depression Scale (HAMD) score $\geq 15$ or patients with vascular dementia with Hachinski Ischemia Scale (>) score 7. (4) Patients who suffer from other serious medical conditions.

For the healthy control: (1) Healthy subjects aged 65-75 years old, same sex as matched AD patients; (2) No major systemic diseases in heart, liver and kidney disease.

\section{Expression spectra of mRNA and IncRNA in AD samples and controls}

$2 \mathrm{ml}$ peripheral blood was taken from three AD patients and three healthy controls populations respectively. RNA was extracted from the AD group and the Control group. Agilent ND-1000 was used to detect RNA degradation and RNA concentration[16]. Samples were labeled with Arraystar RNA Flash Labeling Kit[17]. After hybridizing, incubating and washing, the chip was scanned using Agilent RNA Microarray Scanner. Agilent Feature Extraction software (V11.0.1.1) was used to collect the chip probe signal value[18]. Agilent GeneSpring GX V12.1 software was used for chip quantile standardization. The microarray data have been uploaded in the National Center for Biotechnology Information Gene Expression Omnibus (GEO, https://www.ncbi.nlm.nih.gov/geo/) [GSE 182910: GEO].

\section{Differential expression analysis}

Comparing gene profiles of $A D$ and healthy control, fold change ( $F C$, the ratio of the group average) in each IncRNA was calculated. $t$-test was used to estimate the statistical significance. LncRNAs with FC $\geq$ 2.0 and $P$ value $\leq 0.05$ was selected as the differentially expressed genes. Microsoft Excel's Data/Sort \& Filter functionalities were used to filter the analysis output, and the differentially expressed LncRNAs was sorted according to the fold change and $P$ value.

\section{GO annotation and KEGG pathway enrichment analyses of the DEGs}


Gene Ontology (GO), including biological processes (BPs), cellular components (CCs), molecular functions (MFs) and Kyoto Encyclopedia of Genes and Genomes (KEGG) pathways enrichment analyses of DEGs were performed using the Database for Annotation, Visualization and Integrated Discovery $(P<$ 0.05 as the criteria for enrichment significance)[19].

\section{Protein-Protein Interaction (PPI) Network construction}

In order to further explore the interaction of different target genes and the molecular mechanism of $A D$, we used STRING (https://string-db.org/) to analyze and construct a PPI network. Then the interaction network and the top 50 hub genes were visualized by cytoHubba in Cytoscape. The nodes in the network were represented as target genes, and the lines between two nodes were denoted interactions.

\section{Cell culture}

Human neuroblastoma cell line (SH-SY5Y) was purchased from Beina Cell Bank and cultured in DMEM/F12 complete medium containing $10 \%$ fetal bovine serum and $1 \%$ antibiotics. The cells were cultured in an incubator containing $5 \% \mathrm{CO} 2,95 \%$ humidity and $37^{\circ} \mathrm{C}$. SH-SY $5 Y$ was treated with different concentrations $(0,5,10$, or $20 \mu \mathrm{M})$ of $A \beta$ for $24 \mathrm{~h}$ or $10 \mu \mathrm{M}$ of $A \beta$ for different times $(0,12,24$, or $48 \mathrm{~h})$ to establish in vitro AD cell model. si-RP11-59J16.2, si-RNA negative control (si-NC), si-MCM2, pcDNAMCM2, pcDNA-NC were all purchased from Sangon Biotech (Shanghai) Co., Ltd. The antibody was purchased from Abcam. CCK-8 cell viability detection kit and Annexin V-FITC/PI Cell Apoptosis Assay kit were purchased from BEENbio Biotechnology.

\section{Real-time quantitative PCR}

Trizol was used to extract total RNA from each group, and cDNA was obtained by reverse transcription according to the instructions. The reverse transcription system was as follows: RNase Free $\mathrm{dH} 2 \mathrm{O}: 14 \mu \mathrm{l}$, $5 \mathrm{X}$ all in one reverse transcription mix: $2 \mu \mathrm{l}$, RNA: $4 \mu \mathrm{l}, 42^{\circ} \mathrm{C}$ for $15 \mathrm{~min}$ and $85^{\circ} \mathrm{C}$ for $5 \mathrm{~s}$ for reverse

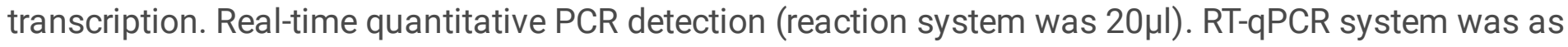
follows: $2 \star$ SYBE green qPCR mix: $10 \mu \mathrm{l}$, cDNA template: $20 \mathrm{ng}$, forward primer $(5 \mu \mathrm{M}): 1 \mu \mathrm{l}$, Reverse primer $(5 \mu \mathrm{M}): 1 \mu \mathrm{l}$, ddH2O: add to $20 \mu \mathrm{l}$, qPCR program: $95^{\circ} \mathrm{C}$ hold for $5 \mathrm{~min}$, and followed 40 cycles as $95^{\circ} \mathrm{C} 30 \mathrm{~s}$ and $60^{\circ} \mathrm{C}$ for $45 \mathrm{~s}$. GAPDH was used as the reference gene, mRNA expression abundance in the treated cells in each group was calculated as $\triangle \mathrm{Ct}(\triangle \mathrm{Ct}=\mathrm{Ct}$ value of target gene - $\mathrm{Ct}$ value of internal reference gene). Target gene primer sequence: MCM2 (For 5'-AGAGGATCGTGGTACTGCTATGGC-3', Rev 5'TTATGGATGGCATAGGGCCTCAGA-3'), RP11-59J16.2 (For 5'-AACAAAACTGGGATGAGAAG-3', Rev 5'GACATTCACAGGTCCTGGAG-3'), GAPDH (For 5'-ACCACAGTCCATGCCATCAC-3', Rev 5'TCCACCACCCTGTTGCTGTA-3').

\section{Cell viability detection}

CCK-8 assay was used to detect the viability of cells cultured in 96-well plate. Then $10 \mu$ l CCK-8 solution was added to each well after treatment according to the experimental procedure. After incubation in darkness for $2 \mathrm{~h}$, the absorbance of each well was measured with an enzyme marker. 


\section{Cell apoptosis detection}

According to the instructions of Annexin V-FITC/PI cell apoptosis detection kit, the cells were resuspended in the PBS after wash for 3 times. Annexin V-FITC $(5 \mu \mathrm{l})$ and PI ( $5 \mu \mathrm{l})$ were added and stained for $10 \mathrm{~min}$ in dark respectively. Then apoptosis rate was detected by flow cytometry.

\section{Western Blot assay}

The cells were washed with PBS for 3 times after treatment and collected with 12000 rpm centrifugation. RIPA was used to lyse cells, then proteins were detected by SDS-PAGE gel electrophoresis and western blot assay. After blocking for 1 hour by 5\% skim milk, the PVDF membrane was incubated with the primary antibody at $4^{\circ} \mathrm{C}$ overnight. The membrane was washed 3 times with Tris-buffered saline Tween, and incubated with secondary antibody at room temperature for $2 \mathrm{~h}$. The immunoreactive bands were visualized by ECL chemiluminescence and the grayscale values of bands were quantified by Image Lab 5.2.1 software. Primary antibodies: MCM2 (1: 2000, ab108935, Abcam), Tau (1: 2000, ab8245, Abcam), GAPDH (1: 2000, ab92676, Abcam). Second antibody: Goat Anti-Rabbit IgG H\&L (HRP) (1: 1000, ab6721, Abcam), Rabbit Anti-Mouse IgG H\&L (HRP) (1: 1000, ab6728, Abcam).

\section{Double luciferase reporter gene}

The MCM2 3 '-UTR sequence and the mutated FSP1 3' -UTR sequence was designed and synthesized. The two target gene fragments were cloned into the dual luciferase reporter vector respectively, and the wild-type vector and its mutant vector of the MCM2 3 '-UTR dual luciferase reporter gene were constructed. The recombinant vector was identified by PCR electrophoresis and gene sequencing to prove that the recombinant vector was constructed successfully. 293T cells were co-transfected with RP1159J16.2 overexpressed or RP11-59J16.2 negative control using lipofectamineTM2000 transfection reagent. $48 \mathrm{~h}$ after transfection, the two recombinant plasmids were analyzed using dual luciferase reporter gene assay (table no. E1960, Promega, Madison, Wisconsin, USA). The dual luciferase reporter gene carrier contains two luciferase genes that can be expressed simultaneously in the same cell, one is firefly luciferase reporter gene, the other is sea renal luciferase reporter gene. Firefly luciferase reporter is the main reporter gene with its fragment cloned into a polyclonal site downstream of the firefly luciferase reporter (Multiple cloning site, MCS). If purpose gene expression were inhibited, the firefly luciferase transcription process would be blocked. Inhibition of the firefly luciferase protein translation would decrease firefly fluorescence value, but not affect the sea renal luciferase expression. So the firefly luciferase activity/sea renal luciferase activity value could determine whether RP11-59J16.2 have direct control effect on MCM2 expression.

\section{Statistical analyses}

SPSS 17.0 (Chicago, IL, USA) statistical software was used to analyze the data. The statistical difference between the two groups was calculated by unpaired $t$-test. Benjamini Hochberg FDR (the FDR cutoff was 0.05) was used for multiple-testing correction. One-way analysis of variance (ANOVA) was used to verify 
the differences between three or more groups. A $P$ value $<0.05$ was considered as statistically significant difference.

\section{Results}

\section{Expression profile of mRNAs and IncRNAs in AD patients and controls}

We studied the expression profile of mRNAs and IncRNAs of the peripheral blood from AD patients and control group. According to the results, totally 2482 up-regulated IncRNAs, 696 down-regulated IncRNAs, 649 up-regulated mRNAs and 559 down-regulated mRNAs (FC $\geq 2.0$ and $P$ value $\leq 0.05)$ were identified. Hierarchical cluster analysis was performed to generate a heat map of differentially expressed IncRNAs and mRNAs (Figure 1A, 1B). We used a scatter plot to compare the distribution of differentially expressed IncRNAs and mRNAs (Figure 2A, 2B). Based on fold change values and $P$ values, a volcano plot was used to show the overall data differential expression distribution of IncRNAs and mRNAs (Figure 3A, 3B). In summary, comparing the IncRNAs and mRNAs expression profile of AD patients and control groups, we found significant differences in IncRNAs and mRNAs expression between the two groups.

\section{Enrichment analyses of the target genes}

We performed GO enrichment and KEGG pathway analysis of the 3178 differentially expressed IncRNAs and 1208 differentially expressed mRNAs to further clarify their functional characteristics (Figure 4). In our research, we found that it is involved in biological processes, cellular component and molecular functions for example G1/S transition of mitotic cell cycle. KEGG analysis also found that the differentially expressed genes in the $A D$ group and the control group were mainly enriched in signal pathway such as cell circulation, synaptic vesicle cycle, neuroactive receptor-ligand interactions, and Glycosphingolipd biosynthesis. (Figure 4A, 4B).

\section{PPI Network Analysis}

The STRING online database was used to distinguish the connections between the target genes. A network composed of 99 nodes and 253 edges was obtained, with a confidence score $>0.4$ as significant. We used ClusterOne in Cytoscape for gene clustering. The top 50 scoring genes were represented by orange circles, and the color shades were used to correlate significance (Figure 5).

\section{RP11-59J16.2 highly expressed in serum of AD patients and AD cell models}

According to the results of bioinformatics analysis and qPCR assay, we found that RP11-59J16.2 was significantly overexpressed in serum of AD patients (Figure6A), We induced SH-SY5Y cells with A 3 to construct the AD cell model to explore the role of RP11-59J16.2 in AD. Expression of RP11-59J16.2 in SHSY5Y cells increased in a $A \beta(0,5,10,20 \mu \mathrm{M})$ dose- and treat time dependent manner (Figure 6B, 6C). In the following experiment, $10 \mu \mathrm{M} A \beta$ treatment for $24 \mathrm{~h}$ was used as the condition to induce AD cell model.

\section{MCM2 low expressed in AD cell model}


To explore the mechanism of RP11-59J16.2 in the development of AD, we found that MCM2 may be the potential targets of RP11-59J16.2 (Figure 7A) according to the bioinformatics analysis. The results of dual luciferase report gene experiment showed that compared to the control group, fluorescein in AD cell model was significantly suppressed after overexpression of RP11-59J16.2 mimics and wild type MCM2. While there was no significant change after overexpression of RP11-59J16.2 mimics and MCM2 mutant (Figure 7B). In addition, qPCR and western blot assay results showed that the expression of MCM2 was significantly decreased in the serum of $A D$ patients (Figure 7C, 7D) and AD cell model (Figure 7E, 7F).

\section{RP11-59J16.2 influenced the cell viability and apoptosis of AD cell model by targeting MCM2}

To investigate the role of RP11-59J16.2 and MCM2 in the development of AD, SH-SY5Y cells treated with $10 \mu \mathrm{M} A \beta$ were transfected with NC, si-RP11-59J16.2, MCM2, si-RP11-59J16.2 + si-NC, si-RP11-59J16.2 + si-MCM2. CCK-8 assay showed that downregulation of RP11-59J16.2 and overexpression of MCM2 significantly increased cell viability of SH-SY5Y cells, comparing to $A \beta$ treatment group. While the cell viability reduced significantly after transfection of si-RP11-59J16.2 + si-MCM2 (Figure 8A). Flow cytometry assay was used to study the effect of RP11-59J16.2 and MCM2 on the apoptosis of SH-SY5Y cells. Compare to control group, si-RP11-59J16.2 and overexpression of MCM2 could significantly decrease the apoptosis of SH-SY5Y cells (Figure 8B, 8C). The cell apoptosis in si-RP11-59J16.2 + siMCM2 transfected group was significantly increased compared with si-RP11-59J16.2 group. It may indicate that RP11-59J16.2 may influence the cell viability and apoptosis to regulate the neuronal injury in $\mathrm{AD}$ by targeting MCM2.

\section{RP11-59J16.2 increased Tau phosphorylation by inhibiting MCM2 in AD cell model}

In order to explore the molecular mechanism of RP11-59J16.2 in the development of AD, qRT-PCR and western blot assay was used to detect the effect of RP11-59J16.2/MCM2 on the expression of p-Tau. The expression of $p$-Tau increased significantly after treated with $A \beta$, but decreased significantly after transfection of si-RP11-59J16.2 or MCM2. Compare to si-RP11-59J16.2 or MCM2 transfection group, the expression of p-Tau increased significantly in si-RP11-59J16.2+siMCM2 transfection group (Figure 9). MCM2 expression significantly reduced after treatment of $A \beta$, while its expression increased significantly after inhibition of RP11-59J16.2 in si-RP11-59J16.2 group (Figure 9B, 9C). These results indicated that RP11-59J16.2 may contribute to AD development through inhibiting of MCM2.

\section{Discussion}

Alzheimer's disease (AD) is a kind of heterogeneity and multifactor progressive neurodegenerative disease with unclear etiology[20-24]. Research showed that the incidence rate of $A D$ has increased dramatically in the world in recent years $[25,26]$. Studying the molecular mechanism of the occurrence and development of $A D$ may provide a theoretical basis for the treatment and prevention of $A D$. Long non-coding RNA (IncRNA) could regulate gene expression in transcription, post-transcription, epigenetics and other aspects, and further regulate cell proliferation, differentiation, apoptosis and other life processes, thus it has been found closely related to the occurrence and development of diseases[27, 28]. 
Several IncRNAs may be involved in the pathological changes of $A D$ through $A \beta$ deposition, synaptic remodeling and memory formation. C. Huaying et al[29] reported that 5 IncRNAs for predicting the prognosis of AD based on competing endogenous RNA networks. Y. Zhang et al[30] found that silenced IncRNA H19 and up-regulated microRNA-129 could accelerate viability and restrain apoptosis of PC12 cells induced by $A \beta$ in a cellular model of $A D$.

In this study, the expression profile of mRNA and IncRNA of the peripheral blood from AD patients was studied. We found that many IncRNAs were abnormally expressed in AD, suggesting that IncRNAs in serum may play an important role in the occurrence and development of AD. The distribution of differentially expressed IncRNAs and mRNAs in AD and healthy controls could be observed from the results of cluster analysis, scatter plot and volcano plot. Subsequently, GO analysis and KEGG analysis were performed on the differentially expressed mRNAs. GO analysis results showed that differentially expressed mRNAs were involved in many biological processes, cell composition and molecular functions, mainly enriched in G1/S transition of mitotic cell cycle, suggesting that G1/S transition of mitotic cell cycle may be involved in the occurrence of Alzheimer's disease. KEGG analysis also found that the differentially expressed genes in AD patients were mainly in the signal pathways including cell circulation, synaptic vesicle cycle, neuroactive receptor-ligand interactions, and Glycosphingolipd biosynthesis. This is consistent with previous studies that synapses are essential for cognitive function and that synaptic loss is a stable pathological phenomenon in $A D[31,32]$. Some studies have confirmed that synaptic loss of cortex and limbic system is closely related to AD cognitive dysfunction[33, 34]. In addition, chronic neuroinflammatory changes are also an important neuropathological process in $A D$. The findings suggest that activation of microglia and astrocytes is involved in the progression of AD, although inflammatory glial responses are thought to be secondary to neuronal death or dysfunction[35]. Sphingomyelin and its metabolites play important roles in several cellular processes and signaling pathway, including neuroinflammation, which in turn contribute to the development of $A D[36]$. Moreover, astrocytes regulate synaptic remodeling by releasing synaptic plasticity and neuronal excitability of neuroactive substances such as glial transmitters such as ATP, glutamate, D-serine and GABA, which bind to receptors in the pre - and post-synaptic membranes[37]. Microglia express pattern recognition receptors (PRRs) that bind to different types of $A \beta[38]$. In vitro experiments confirmed that $A \beta$ activates microglia by binding PRRs, including receptors for advanced glycation end products (RAGE), TLRs and scavenger receptors[39]. Production of pro-inflammatory factors would increase microglial phagocytosis by binding of these pathogen-associated molecular patterns (DAMPs or PAMPs) to PRRs[40]. All above suggest that neuro-activated receptors and ligands are involved in the pathological mechanism of AD.

Recent studies have found that neuronal cell cycle re-entry is involved in the development of $A D[41,42]$. Cell cycle regulators are involved in neuronal migration, neuronal maturation and synaptic plasticity in adult neurons[43]. Cell cycle markers are upregulated and reactivated in response to acute injury such as neurotrophic factor deprivation, DNA damage, oxidative stress, and excitatory toxicity, and lead to the death of sympathetic and cortical neurons at G1/S prior to DNA synthesis $[44,45]$. This suggests that in some specific neuronal phenotypes, many signaling pathways triggered by different environmental conditions may cause cell cycle activation and cell death. It is consistent with our results of GO analysis 
and KEGG analysis which showed that differentially expressed genes are mainly enriched in G1/S transition of mitotic cell cycle and cell cycle signaling pathway. Therefore, our results also prove the involvement of the cell cycle in the pathogenesis of AD.

MCM2 encodes the microchromosome maintenance complex (MCM), a key factor in the initiation of genome replication in eukaryotes[46]. Previous studies have demonstrated that MCM2 is expressed in aging hippocampus[47]. MCM2 has been reported to play an important role in the development of $A D$. Wharton SB et al[47] reported that the expression of the MCM2 was associated with the burden of Alzheimer-type pathology. Bonda DJ et al[15]proved that phosphorylated MCM2 (pMCM2) was markedly associated with neurofibrillary tangles, neuropil threads, and dystrophic neurites in AD. Their results provided further evidence for cell cycle aberrations in $A D$ and they also found that cytoplasmic localization of pMCM2 may explain resultant cell cycle stasis and consequent neuronal degeneration[15]. The study of Mezache L[48] showed that as a marker of the neuroprogenitor cells, the expression of MCM2 was significantly reduced in the Alzheimer sections that contained the hyperphosphorylated Tau.

Based on our results of bioinformatics analysis, totally, 649 mRNAs and 2521 IncRNAs were differentially up-regulated and 577 mRNAs and 735 IncRNAs were down-regulated in AD. RP11-59J16.2 was significantly overexpressed in serum of AD patients, while MCM2 was significantly reduced. The result was consistent in AD cell model (SH-SY5Y cells which treated with $10 \mu \mathrm{M} \mathrm{A \beta} \mathrm{1-42).} \mathrm{The} \mathrm{relationship}$ between AD pathological mechanism and RP11-59J16.2/MCM2 is unclear. Subsequent results showed that MCM2 was the direct target of RP11-59J16.2 and RP11-59J16.2 could regulate the expression of MCM2. Our results suggested that RP11-59J16.2 might affect cell viability and apoptosis in AD cell model by inhibiting $\mathrm{MCM} 2$, which consist to the idea that cell cycle re-entry may cause neuronal death by apoptosis[49]. Then the molecular mechanism of RP11-59J16.2 in the development of AD was further investigated. The expression of p-Tau increased decreased significantly with the transfection of si-RP1159J16.2 or MCM2 transfection. After inhibition of MCM2 by co-transfection with si-MCM2, the expression of p-Tau increased significantly. Those results showed that RP11-59J16.2 could increase Tau phosphorylation through inhibiting MCM2 expression in SH-SY5Y cells treated by $A \beta$.

Although the present study provided a new IncRNA- RP11-59J16.2 probably related to the development of $A D$ by affecting cell apoptosis and Tau phosphorylation through regulation of MCM2, it still had some limitations. First, the sample size for microarray analysis was small, which may affect the validity of sequencing results. Secondly, the microarray analysis samples we collected were serum samples of patients, which may be affected by many other external factors. Microarray analysis of cerebrospinal fluid would improve the specificity of the results. However, patients and controls rarely cooperate to complete the lumbar puncture invasive examination clinically. Finally, no in vivo experiments were performed. Future studies need to explore the downstream mechanism of MCM2 on Tau phosphorylation, cell apoptosis and cell-cycle activation in AD.

\section{Conclusion}


Together our data suggest that, RP11-59J16.2 may contribute to the development of AD via regulation of MCM2 on apoptosis and Tau phosphorylation. Our results may illustrate that RP11-59J16.2 might be a potential target molecule for the prediction, diagnosis and treatment of AD. Still, further studies about its molecular mechanism should be explored in vivo.

\section{Abbreviations}

AD: Alzheimer's disease

IncRNA: long non-coding RNA

MCM2: Mini-chromosome maintenance complex component 2

NINCDS-ADRDA: National Institute of Neurological and Communicative Disorders and Stroke/Alzheimer's disease Criteria

HAMD: Hamilton Depression Scale

GO: Gene Ontology

KEGG: Kyoto Encyclopedia of Genes and Genomes

PPI: Protein-Protein Interaction

SH-SY5Y: Human neuroblastoma cell line

\section{Declarations}

\section{Acknowledgements}

This research did not receive any specific grant from agencies in the public, commercial, or not-for-profit sectors.

\section{Statement of interest}

All authors of this paper declare that there is no conflict of interest related to the content of this manuscript.

\section{Funding}

The work was supported by the Foundation from the First Affiliated hospital of Harbin Medical University (project 2016B004).

\section{Author information}


Department of Neurology, the First Affiliated Hospital of Harbin Medical University, Harbin, Heilongjiang, 150001, China.

Fulin Guan

Integrated Chinese and Western Medicine Department, The First Affiliated Hospital of Harbin Medical University, Harbin, Heilongjiang, 150001, China.

Lei Li

The First Affiliated Hospital of Harbin Medical University, Harbin, Heilongjiang, 150001, China.

Qichang Gao \& Jiaao Gu

Haiyuan Hospital of Heilongjiang, Harbin, Heilongjiang, 150001, China.

Xinghua Dai

Heilongjiang University of Chinese Medicine, Harbin, Heilongjiang, 150040, China.

Rui Bao

\section{AUTHOR CONTRIBUTIONS}

FG and QG contributed equally to this work. They designed and performed the majority of the experiments, wrote and edited the manuscript. JG contributed important reagents and provided technical assistance. XD collected and analyzed the data. RB helped with revising the manuscript. LL supervised and assisted the process of work.

\section{Ethics declarations}

The studies involving human participants were reviewed and approved by first Affiliated Hospital of Harbin Medical University, Harbin, China. The patients/participants provided their written informed consent to participate in this study.

\section{Consent for publication}

All patients or relatives of the organization donors were fully understood the purpose and plan of the study, and agreed to publish the results of the study. Subsequently, a written informed consent was obtained.

\section{Statement of interest}

The authors declare that they have no competing interests.

\section{Availability of supporting data}


The microarray data have been uploaded in the National Center for Biotechnology Information Gene Expression Omnibus (GEO, https://www.ncbi.nlm.nih.gov/geo/) [GSE 182910: GEO]

\section{References}

1. Galvão F, Jr., Grokoski KC, da Silva BB, Lamers ML, Siqueira IR: The amyloid precursor protein (APP) processing as a biological link between Alzheimer's disease and cancer. Ageing Res Rev 2019, 49:83-91.

2. Tarditi A, Caricasole A, Terstappen G: Therapeutic targets for Alzheimer's disease. Expert Opin Ther Targets 2009, 13(5):551-567.

3. Toffa DH, Magnerou MA, Kassab A, Hassane Djibo F, Sow AD: Can magnesium reduce central neurodegeneration in Alzheimer's disease? Basic evidences and research needs. Neurochem Int 2019, 126:195-202.

4. Brosnan CA, Voinnet O: The long and the short of noncoding RNAs. Curr Opin Cell Biol 2009, 21(3):416-425.

5. Guttman M, Amit I, Garber M, French C, Lin MF, Feldser D, Huarte M, Zuk O, Carey BW, Cassady JP et al: Chromatin signature reveals over a thousand highly conserved large non-coding RNAs in mammals. Nature 2009, 458(7235):223-227.

6. Shi X, Sun M, Liu H, Yao Y, Song Y: Long non-coding RNAs: a new frontier in the study of human diseases. Cancer Lett 2013, 339(2):159-166.

7. Chen $L$, Zhou Y, Li H: LncRNA, miRNA and IncRNA-miRNA interaction in viral infection. Virus Res 2018, 257:25-32.

8. Gutschner T, Diederichs S: The hallmarks of cancer: a long non-coding RNA point of view. RNA Biol 2012, 9(6):703-719.

9. Paraskevopoulou MD, Hatzigeorgiou AG: Analyzing MiRNA-LncRNA Interactions. Methods Mol Biol 2016, 1402:271-286.

10. Sun D, Zhong J, Wei W, Liu L, Liu J, Lin X: Long non-coding RNAs Inc-ANGPTL1-3:3 and Inc-GJA1012:1 present as regulators of sentinel lymph node metastasis in breast cancer. Oncol Lett 2020, 20(5):188.

11. Gottesman MM, Fojo T, Bates SE: Multidrug resistance in cancer: role of ATP-dependent transporters. Nat Rev Cancer 2002, 2(1):48-58.

12. Randell JC, Bowers JL, Rodríguez HK, Bell SP: Sequential ATP hydrolysis by Cdc6 and ORC directs loading of the Mcm2-7 helicase. Mol Cell 2006, 21(1):29-39.

13. Kucherlapati M: Examining transcriptional changes to DNA replication and repair factors over uveal melanoma subtypes. BMC Cancer 2018, 18(1):818.

14. Blow JJ, Dutta A: Preventing re-replication of chromosomal DNA. Nat Rev Mol Cell Biol 2005, 6(6):476-486. 
15. Bonda DJ, Evans TA, Santocanale C, Llosá JC, Viña J, Bajic V, Castellani RJ, Siedlak SL, Perry G, Smith MA et al: Evidence for the progression through S-phase in the ectopic cell cycle reentry of neurons in Alzheimer disease. Aging (Albany NY) 2009, 1(4):382-388.

16. Aranda Rt, Dineen SM, Craig RL, Guerrieri RA, Robertson JM: Comparison and evaluation of RNA quantification methods using viral, prokaryotic, and eukaryotic RNA over a 10(4) concentration range. Anal Biochem 2009, 387(1):122-127.

17. Shi Y, Shang J: Long Noncoding RNA Expression Profiling Using Arraystar LncRNA Microarrays. Methods Mol Biol 2016, 1402:43-61.

18. Zahurak M, Parmigiani G, Yu W, Scharpf RB, Berman D, Schaeffer E, Shabbeer S, Cope L: Preprocessing Agilent microarray data. BMC Bioinformatics 2007, 8:142.

19. Chen L, Zhang YH, Wang S, Zhang Y, Huang T, Cai YD: Prediction and analysis of essential genes using the enrichments of gene ontology and KEGG pathways. PLoS One 2017, 12(9):e0184129.

20. Bredesen DE, Amos EC, Canick J, Ackerley M, Raji C, Fiala M, Ahdidan J: Reversal of cognitive decline in Alzheimer's disease. Aging (Albany NY) 2016, 8(6):1250-1258.

21. Barker WW, Luis CA, Kashuba A, Luis M, Harwood DG, Loewenstein D, Waters C, Jimison P, Shepherd E, Sevush S et al: Relative frequencies of Alzheimer disease, Lewy body, vascular and frontotemporal dementia, and hippocampal sclerosis in the State of Florida Brain Bank. Alzheimer Dis Assoc Disord 2002, 16(4):203-212.

22. Bredesen DE: Inhalational Alzheimer's disease: an unrecognized - and treatable - epidemic. Aging (Albany NY) 2016, 8(2):304-313.

23. Huang Y, Mucke L: Alzheimer mechanisms and therapeutic strategies. Cell 2012, 148(6):1204-1222.

24. Breteler MM: Vascular risk factors for Alzheimer's disease: an epidemiologic perspective. Neurobiol Aging 2000, 21(2):153-160.

25. Guerriero F, Sgarlata C, Francis M, Maurizi N, Faragli A, Perna S, Rondanelli M, Rollone M, Ricevuti G: Neuroinflammation, immune system and Alzheimer disease: searching for the missing link. Aging Clin Exp Res 2017, 29(5):821-831.

26. Fratiglioni L, Winblad B, von Strauss E: Prevention of Alzheimer's disease and dementia. Major findings from the Kungsholmen Project. Physiol Behav 2007, 92(1-2):98-104.

27. Wu Q, Meng WY, Jie Y, Zhao H: LncRNA MALAT1 induces colon cancer development by regulating miR-129-5p/HMGB1 axis. J Cell Physio/ 2018, 233(9):6750-6757.

28. Wei W, Liu Y, Lu Y, Yang B, Tang L: LncRNA XIST Promotes Pancreatic Cancer Proliferation Through miR-133a/EGFR. J Cell Biochem 2017, 118(10):3349-3358.

29. Huaying C, Xing J, Luya J, Linhui N, Di S, Xianjun D: A Signature of Five Long Non-Coding RNAs for Predicting the Prognosis of Alzheimer's Disease Based on Competing Endogenous RNA Networks. Front Aging Neurosci 2020, 12:598606.

30. Zhang YY, Bao HL, Dong LX, Liu Y, Zhang GW, An FM: Silenced IncRNA H19 and up-regulated microRNA-129 accelerates viability and restrains apoptosis of PC12 cells induced by $A \beta(25-35)$ in a 
cellular model of Alzheimer's disease. Cell Cycle 2021, 20(1):112-125.

31. Scheff SW, Neltner JH, Nelson PT: Is synaptic loss a unique hallmark of Alzheimer's disease? Biochem Pharmacol 2014, 88(4):517-528.

32. Selkoe DJ: Alzheimer's disease is a synaptic failure. Science 2002, 298(5594):789-791.

33. Terry RD, Masliah E, Salmon DP, Butters N, DeTeresa R, Hill R, Hansen LA, Katzman R: Physical basis of cognitive alterations in Alzheimer's disease: synapse loss is the major correlate of cognitive impairment. Ann Neurol 1991, 30(4):572-580.

34. DeKosky ST, Scheff SW: Synapse loss in frontal cortex biopsies in Alzheimer's disease: correlation with cognitive severity. Ann Neuro/ 1990, 27(5):457-464.

35. Lampron A, Elali A, Rivest S: Innate immunity in the CNS: redefining the relationship between the CNS and Its environment. Neuron 2013, 78(2):214-232.

36. de Wit NM, Mol K, Rodríguez-Lorenzo S, de Vries HE, Kooij G: The Role of Sphingolipids and Specialized Pro-Resolving Mediators in Alzheimer's Disease. Front Immunol 2020, 11:620348.

37. Nanclares C, Baraibar AM, Araque A, Kofuji P: Dysregulation of Astrocyte-Neuronal Communication in Alzheimer's Disease. Int J Mol Sci 2021, 22(15).

38. Venegas C, Heneka MT: Danger-associated molecular patterns in Alzheimer's disease. J Leukoc Biol 2017, 101(1):87-98.

39. Sarlus H, Heneka MT: Microglia in Alzheimer's disease. J Clin Invest 2017, 127(9):3240-3249.

40. Pan XD, Zhu YG, Lin N, Zhang J, Ye QY, Huang HP, Chen XC: Microglial phagocytosis induced by fibrillar $\beta$-amyloid is attenuated by oligomeric $\beta$-amyloid: implications for Alzheimer's disease. $\mathrm{Mol}$ Neurodegener 2011, 6:45.

41. McShea A, Lee HG, Petersen RB, Casadesus G, Vincent I, Linford NJ, Funk JO, Shapiro RA, Smith MA: Neuronal cell cycle re-entry mediates Alzheimer disease-type changes. Biochim Biophys Acta 2007, 1772(4):467-472.

42. Neve RL, McPhie DL: Dysfunction of amyloid precursor protein signaling in neurons leads to DNA synthesis and apoptosis. Biochim Biophys Acta 2007, 1772(4):430-437.

43. Lim S, Kaldis P: Cdks, cyclins and CKIs: roles beyond cell cycle regulation. Development 2013, 140(15):3079-3093.

44. Becker EB, Bonni A: Cell cycle regulation of neuronal apoptosis in development and disease. Prog Neurobio/ 2004, 72(1):1-25.

45. Liu DX, Greene LA: Neuronal apoptosis at the G1/S cell cycle checkpoint. Cell Tissue Res 2001, 305(2):217-228.

46. Lei M, Kawasaki Y, Young MR, Kihara M, Sugino A, Tye BK: Mcm2 is a target of regulation by Cdc7Dbf4 during the initiation of DNA synthesis. Genes Dev 1997, 11(24):3365-3374.

47. Wharton SB, Williams GH, Stoeber K, Gelsthorpe CH, Baxter L, Johnson AL, Ince PG: Expression of $\mathrm{Ki} 67, \mathrm{PCNA}$ and the chromosome replication licensing protein $\mathrm{Mcm} 2$ in glial cells of the ageing 
human hippocampus increases with the burden of Alzheimer-type pathology. Neurosci Lett 2005, 383(1-2):33-38.

48. Mezache L, Mikhail M, Garofalo M, Nuovo GJ: Reduced miR-512 and the Elevated Expression of Its Targets cFLIP and MCL1 Localize to Neurons With Hyperphosphorylated Tau Protein in Alzheimer Disease. Appl Immunohistochem Mol Morphol 2015, 23(9):615-623.

49. Yang Y, Mufson EJ, Herrup K: Neuronal cell death is preceded by cell cycle events at all stages of Alzheimer's disease. J Neurosci 2003, 23(7):2557-2563.

\section{Figures}

A

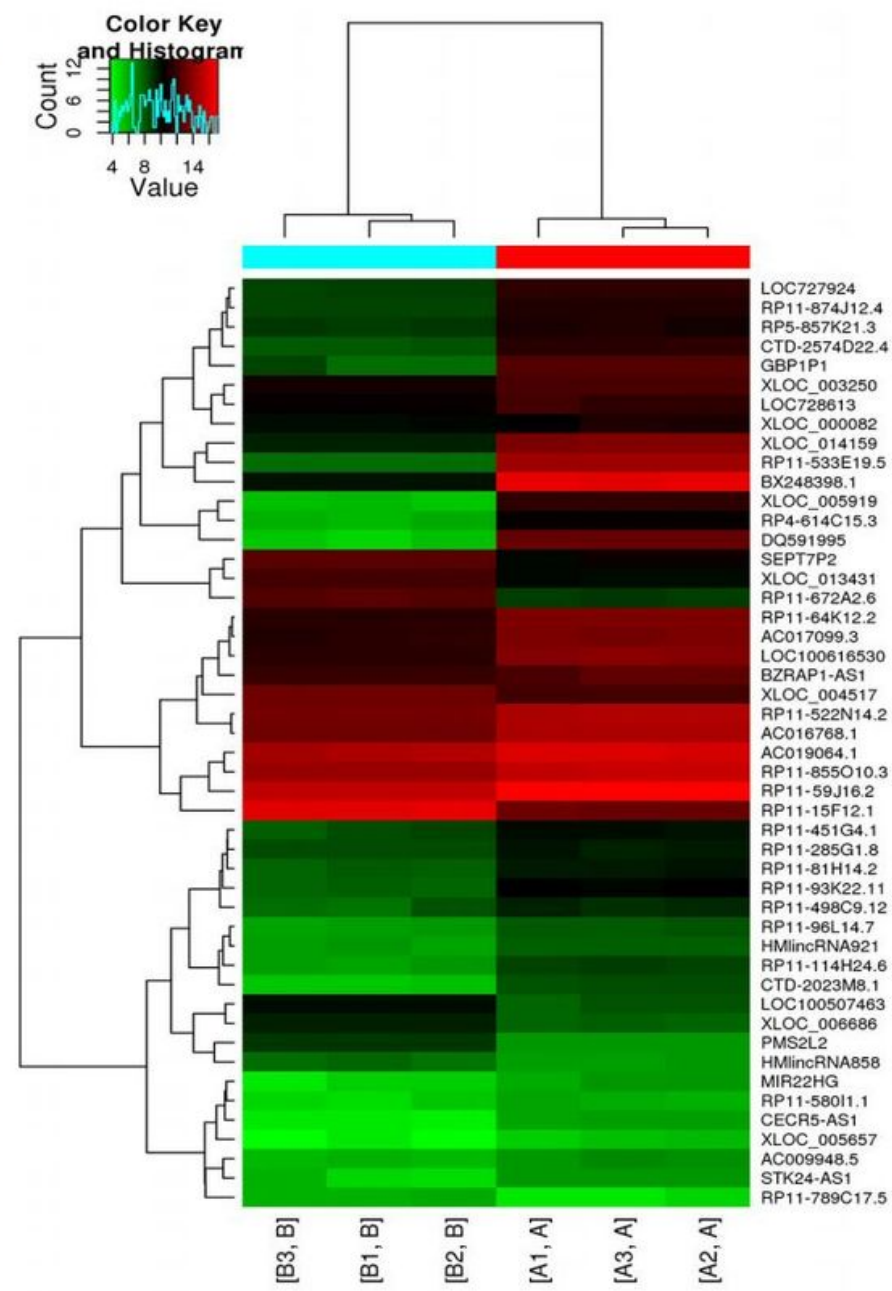

B
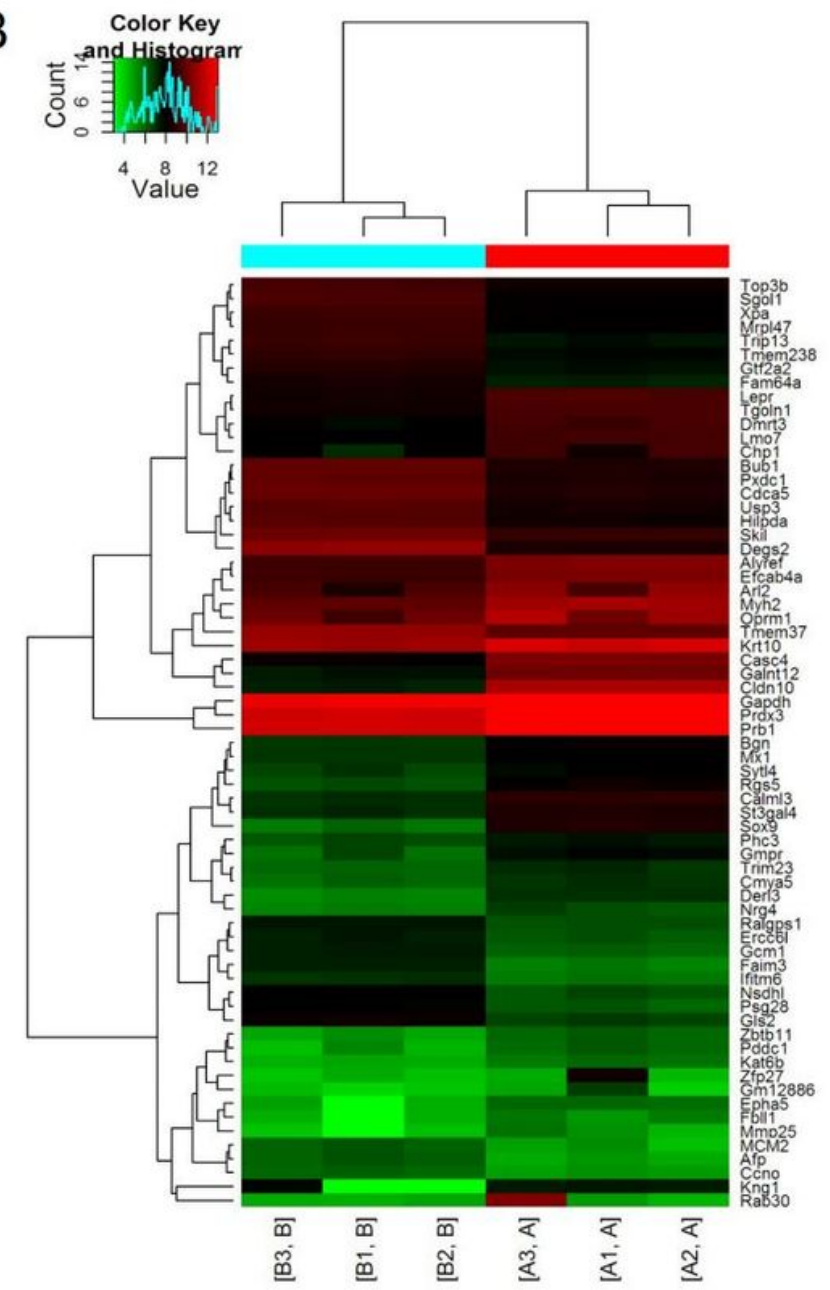

Figure 1

Cluster heat map of mRNA and IncRNA in AD and control. (A) Cluster heat map of IncRNA. (B) Cluster heat map of mRNA. Red represents up-regulated genes and green represents down-regulated genes. 
A

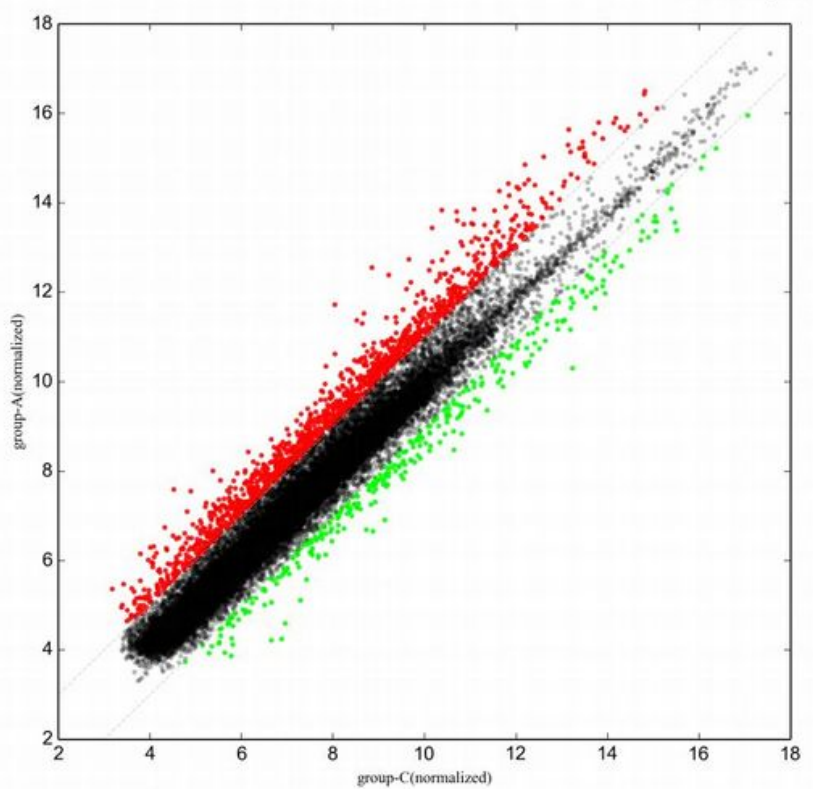

B

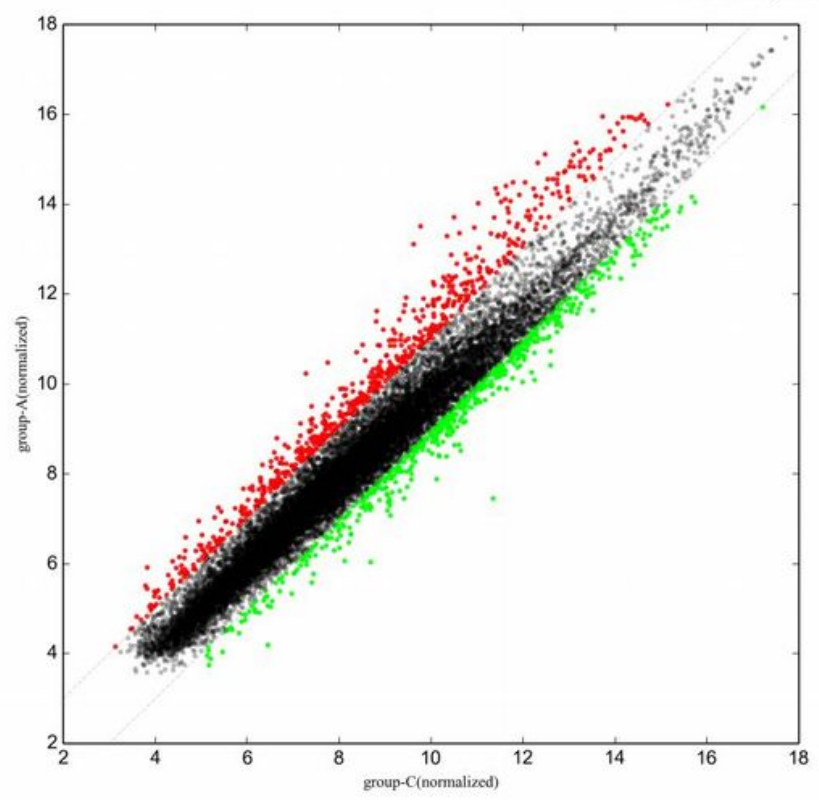

Figure 2

Scatter plot of mRNA and IncRNA in AD and control. (A) Scatter plot of IncRNA. (B) Scatter plot of mRNA. Red represents up-regulated genes and green represents down-regulated genes.
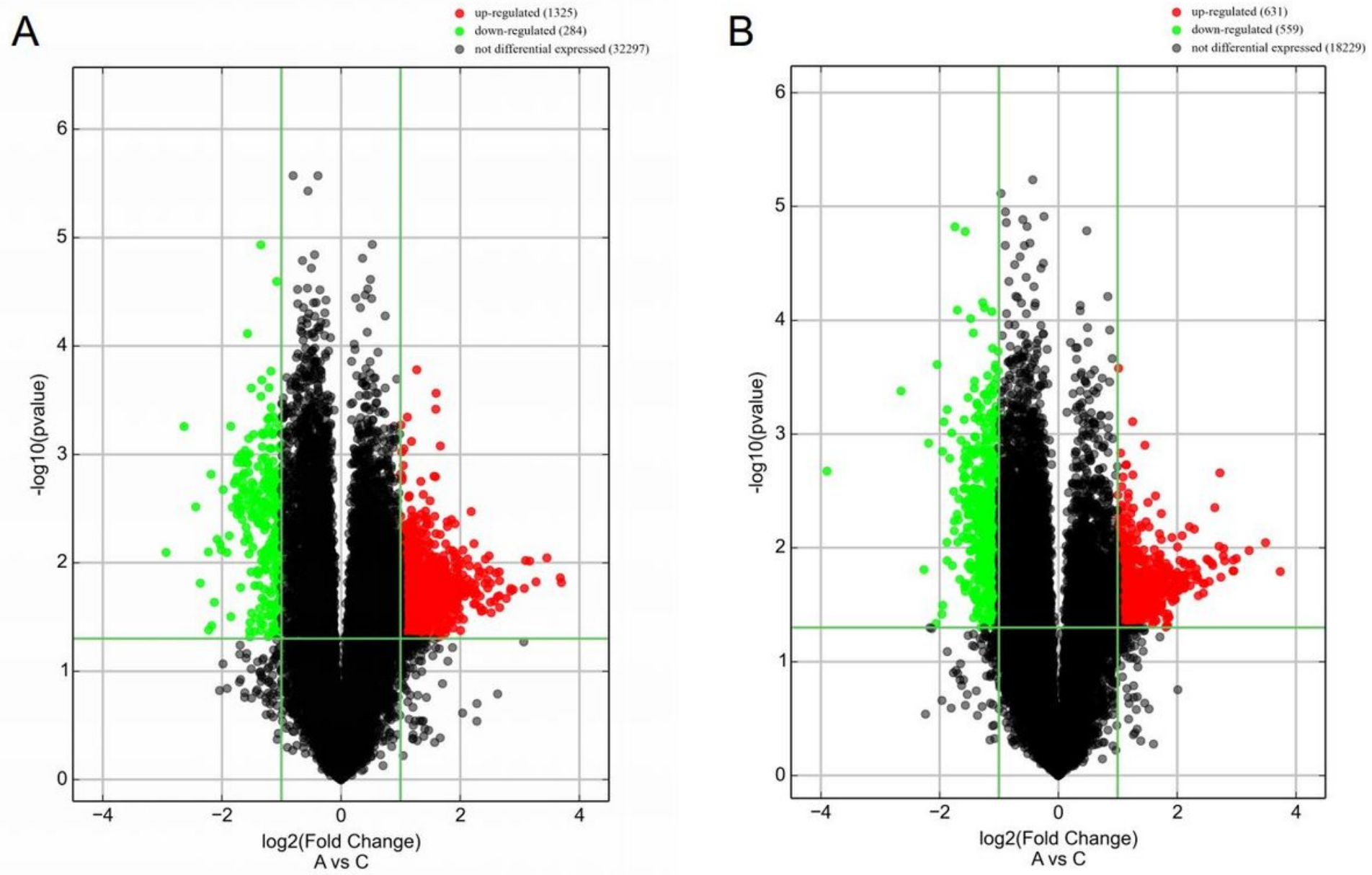


\section{Figure 3}

Volcano plot of mRNA and IncRNA in AD and control. (A) Volcano plot of IncRNA. (B) Volcano plot of mRNA. $X$-axis parallel line: $P=0.05$; $Y$-axis parallel line: $F C$ value $=2$. Red area, $P<0.05, F C \geq 2$ differential genes; Green area, $\mathrm{P}<0.05, \mathrm{FC} \leq 0.5$ differential genes.

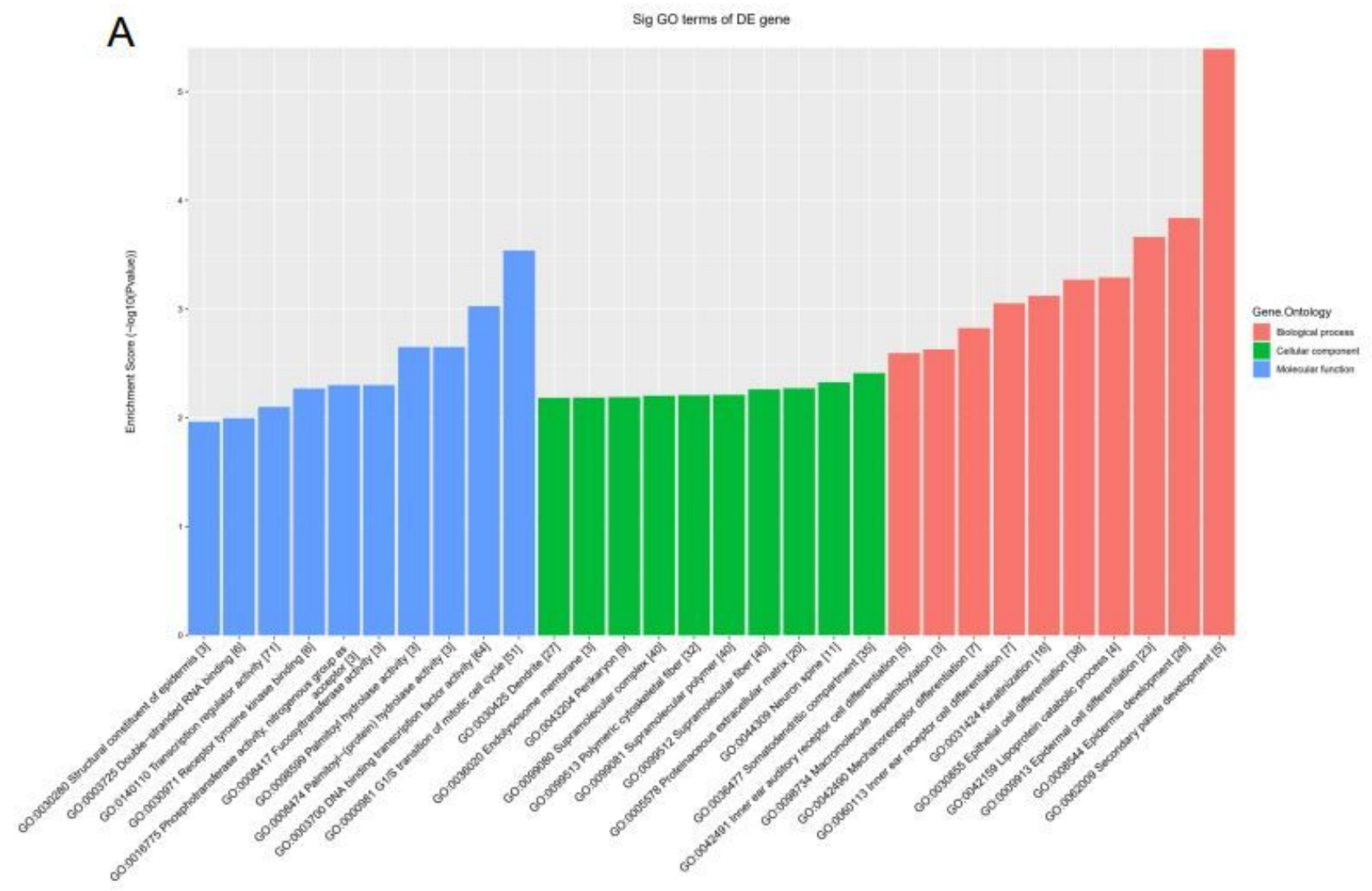

B

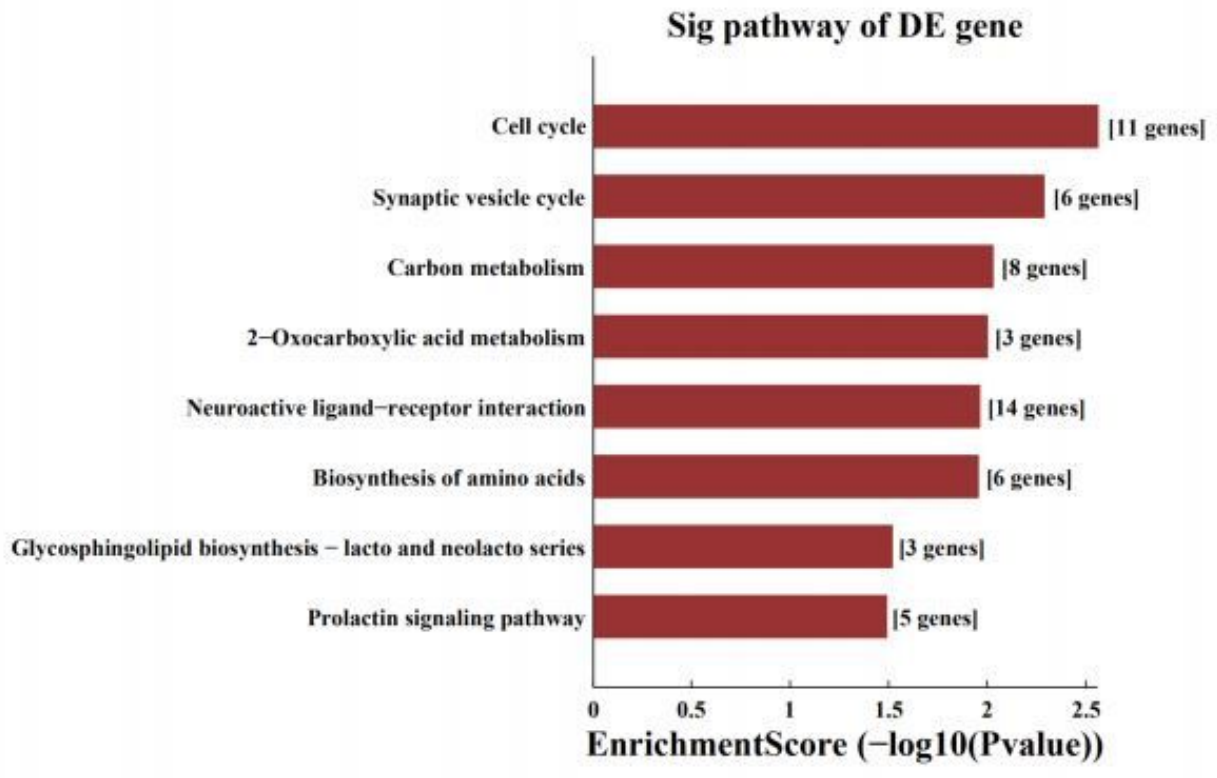

Figure 4 
GO enrichment and KEGG pathway analysis of differentially expressed genes. (A) GO analysis of differentially expressed mRNA between $A D$ and control group. (B) KEGG analysis of differentially expressed mRNA between AD and control group.

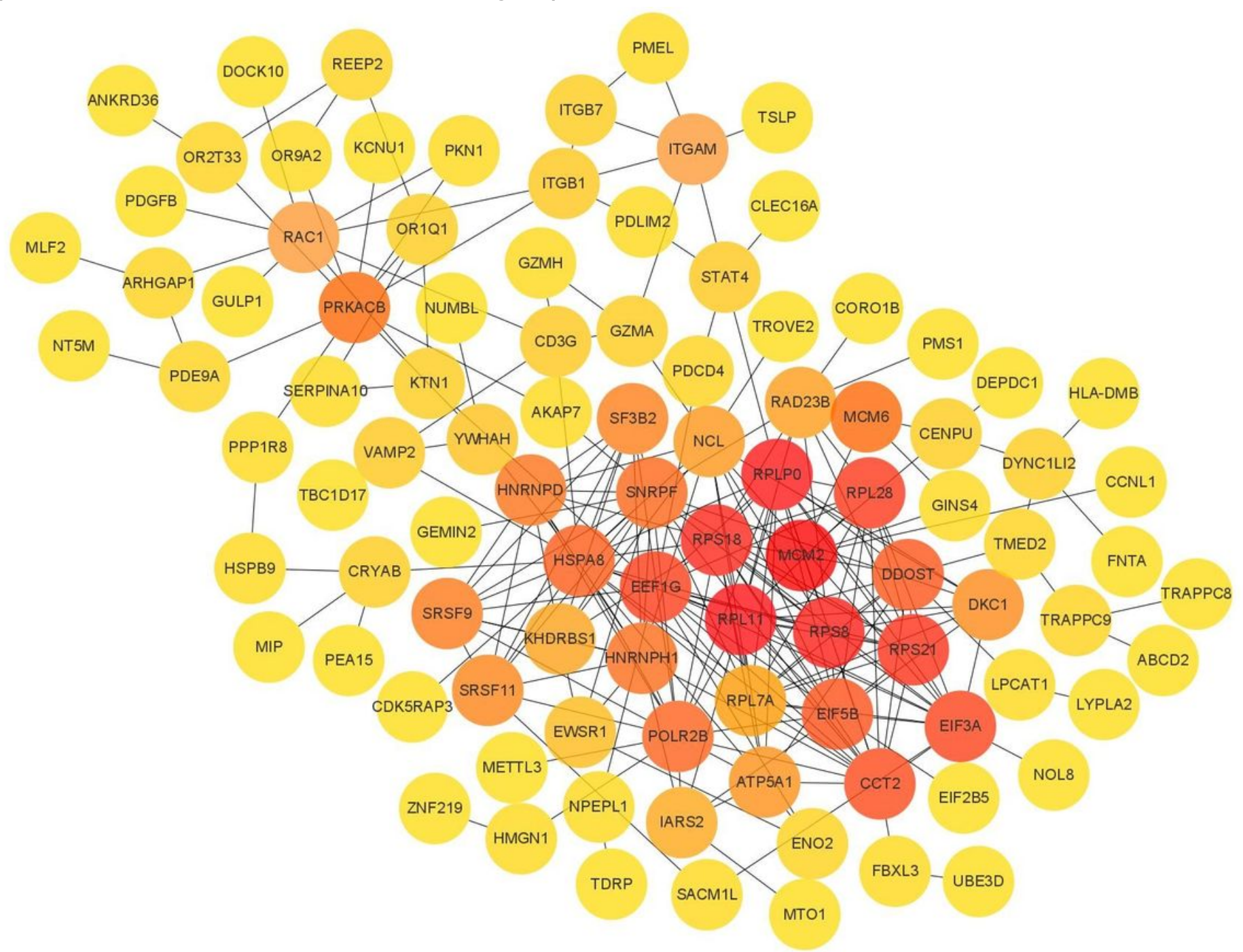

\section{Figure 5}

PPI network analysis of mRNA.
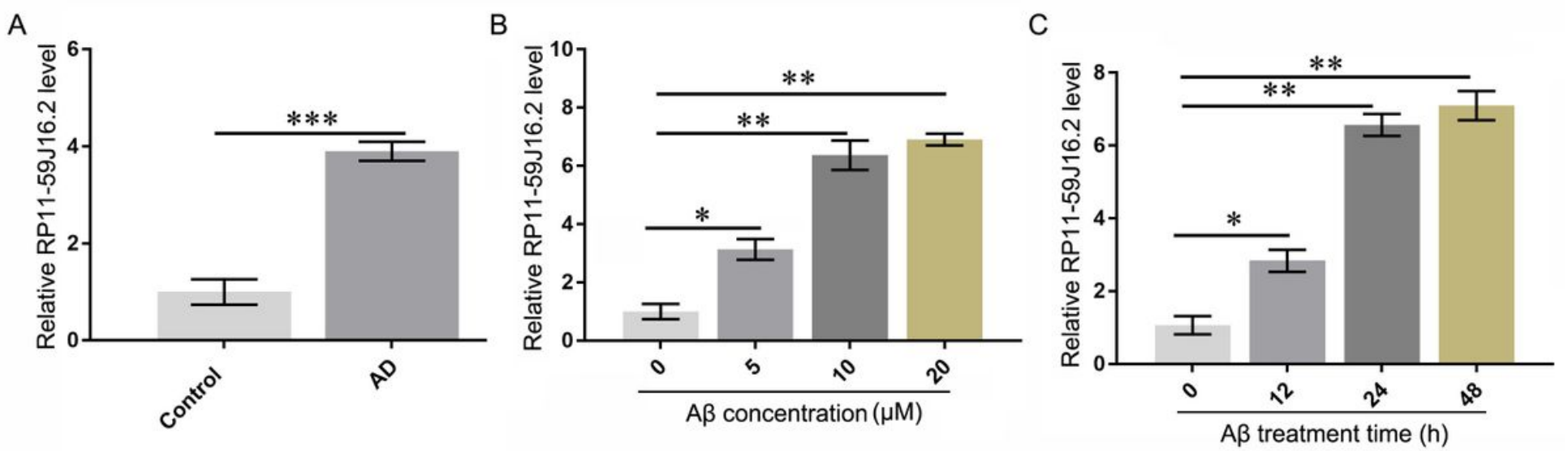

Figure 6 
RP11-59J16.2 was overexpressed in serum of $A D$ patients and A 3 treated SH-SY5Y cell model. (A) RP11$59 \mathrm{~J} 16.2$ was highly expressed in serum of AD patients. (B) Expression of RP11-59J16.2 was detected in SH-SY5Y after qRT-PCR treatment at different concentrations of $A \beta 1-42(0,5,10,20 \mu \mathrm{M})$ for $24 \mathrm{~h}$. C. Expression of RP11-59J16.2 was detected in SH-SY5Y after treatment with 10 $\mu \mathrm{M} \mathrm{A \beta 1-42} \mathrm{at} \mathrm{different}$ times $(0,12,24,48 \mathrm{~h})$. The experiment was repeated three times in each group, ${ }^{\star} P<0.05$; $* \star P<0.01$; *** $P<0.001$.

A

Site: Chromosome 3: 127,489,553-127,490,787

RP11-59J16.2 5',......agtagggagggettcetggagt $\cdots . .3$,

MCM2 3, $\quad \| . .$. cetccaggggecectetgtgec....5,

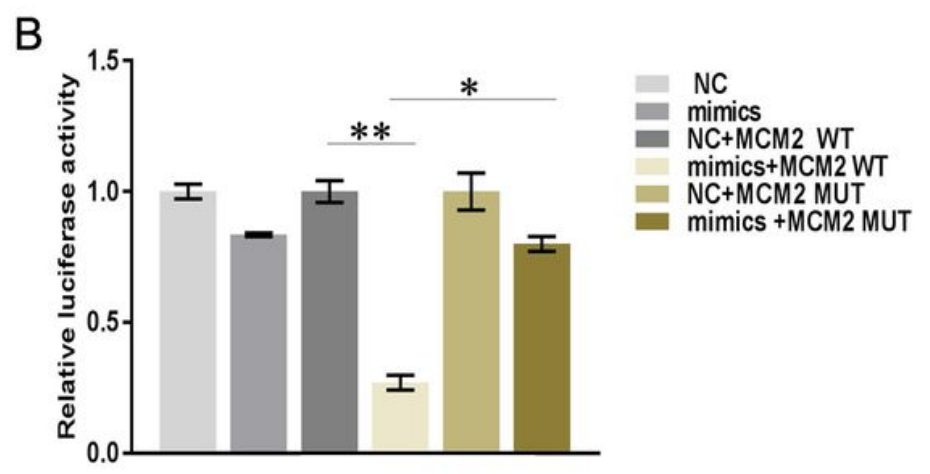

C

D
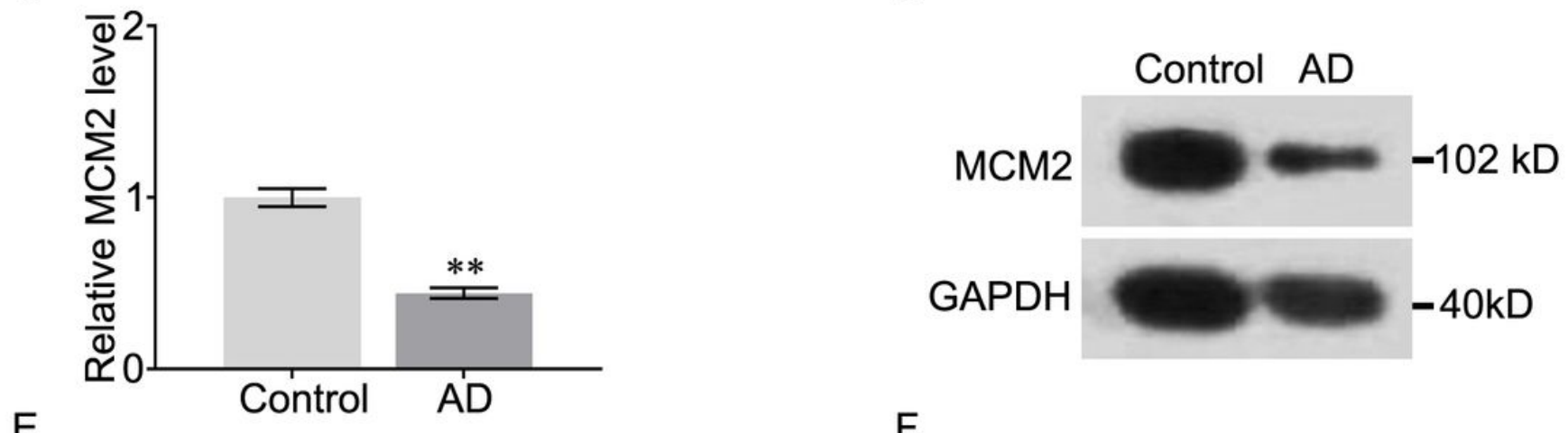

$\mathrm{E}$
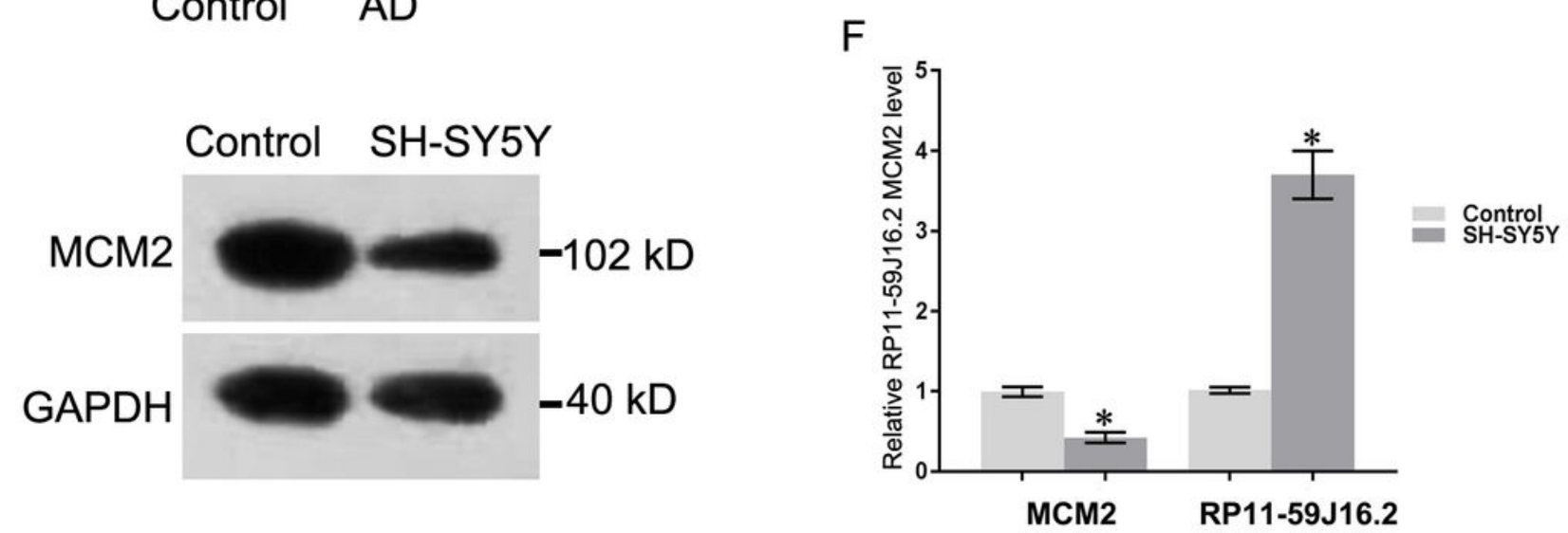

Figure 7

RP11-59J16.2 targetly regulate the expression of MCM2 which was low expressed AD serum and cell model. (A) Bioinformatics analysis of the binding sites of RP11-59J16.2 and MCM2. (B) Double luciferase reporter gene assay verified the binding sites of RP11-59J16.2 and MCM2. (C, D) Low expression of MCM2 in serum of AD patients by qRT-PCR and Western blot. (E) MCM2 was low expressed in AD cell model by Western blot. (F) qRT-PCR confirmed high expression of RP11-59J16.2 and low 
expression of MCM2 with positive correlation in AD cell model. The experiment was repeated three times in each group, * $\mathrm{P}<0.05 ;$ ** $\mathrm{P}<0.01$.

A

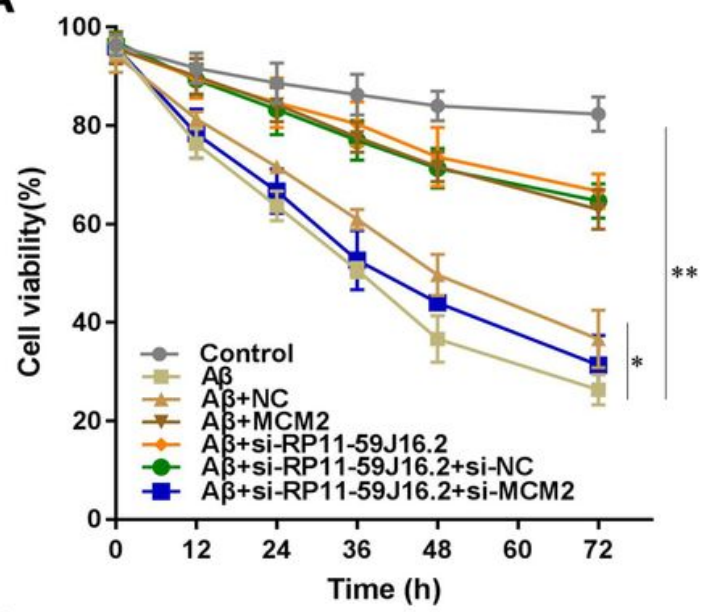

B

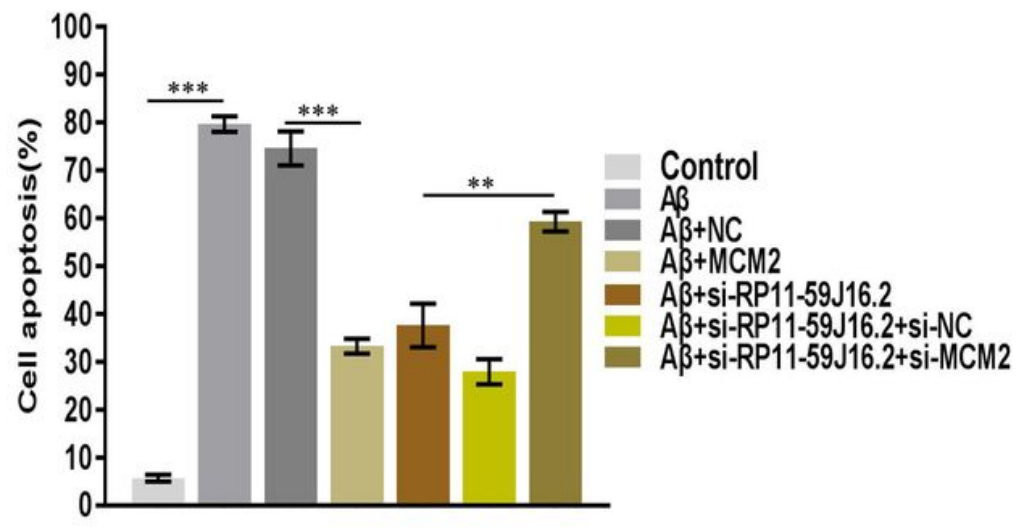

C
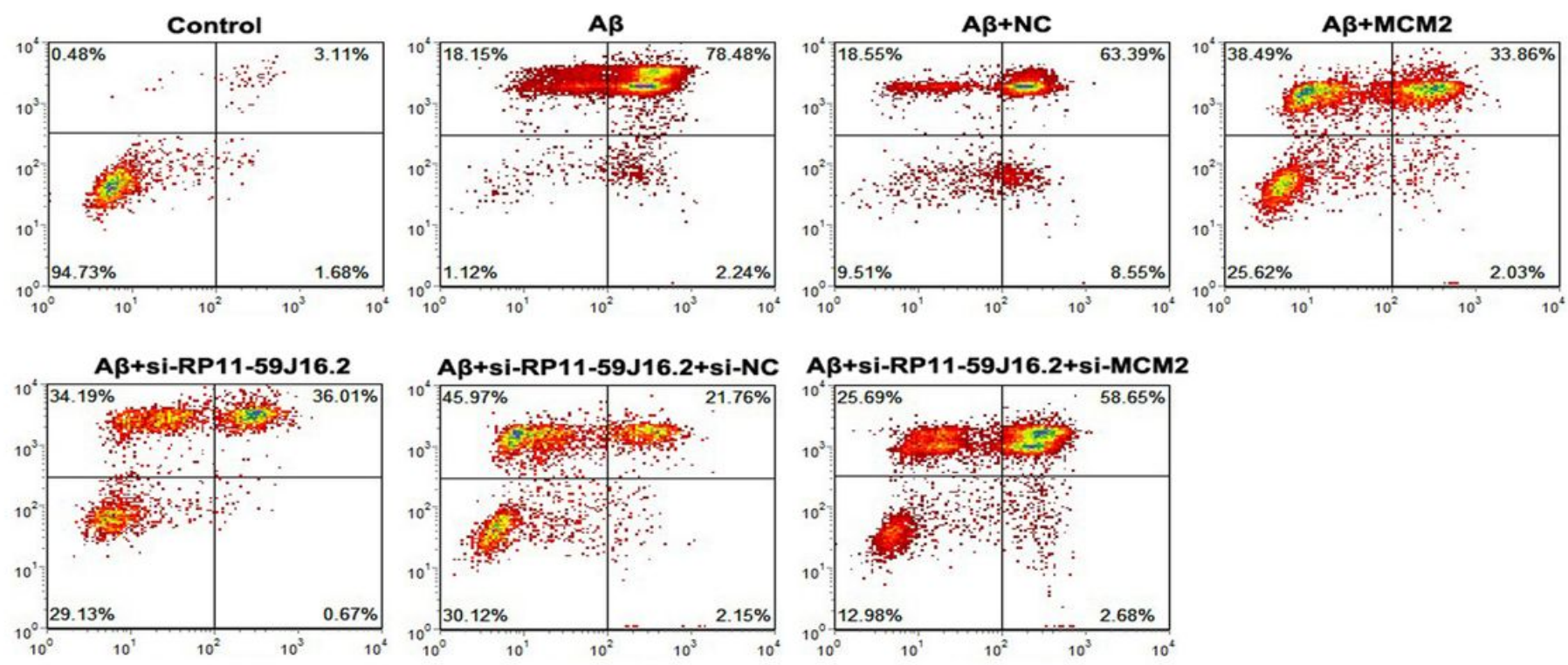

\section{Figure 8}

RP11-59J16.2 affect the neuronal damage of SH-SY5Y cells induced by A $\beta$ by targeting MCM2. After

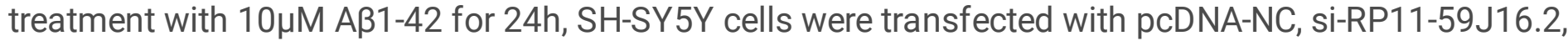
pcDNA-MCM2, si-RP11-59J16.2 + si-NC and si-RP11-59J16.2 + si-MCM2 to detect cell viability (A) and apoptosis (B, C). (A) CCK-8 assay was used to detect the changes of cell viability in each group. Cell viability increased significantly in si-RP11-59J16.2 and MCM2 transfection group compared to $A \beta$ treatment group. It reduced significantly after transfection of si-RP11-59J16.2+ si-MCM2. (B, C) Flow cytometry was used to explore the effects of RP11-59J16.2 and MCM2 on apoptosis of SH-SY5Y cells. Transfection of si-RP11-59J16.2 or MCM2 significantly reduced the apoptosis of SH-SY5Y cells after A $\beta$ treatment. The cell apoptosis in si-RP11-59J16.2+ si-MCM2 group was significantly increased compared with si-RP11-59J16.2 group. The experiment was repeated three times in each group, ${ }^{*} \mathrm{P}<0.05$; $* * \mathrm{P}<$ $0.01 ; * \star \star ~ P<0.001$. 
A

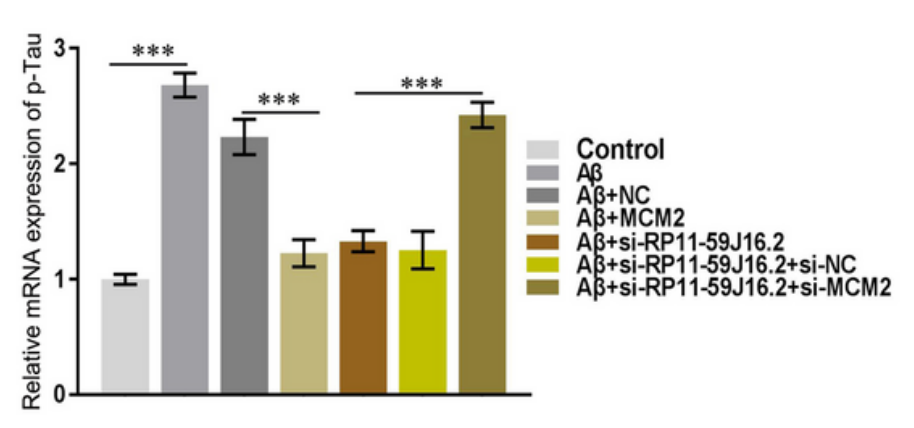

C

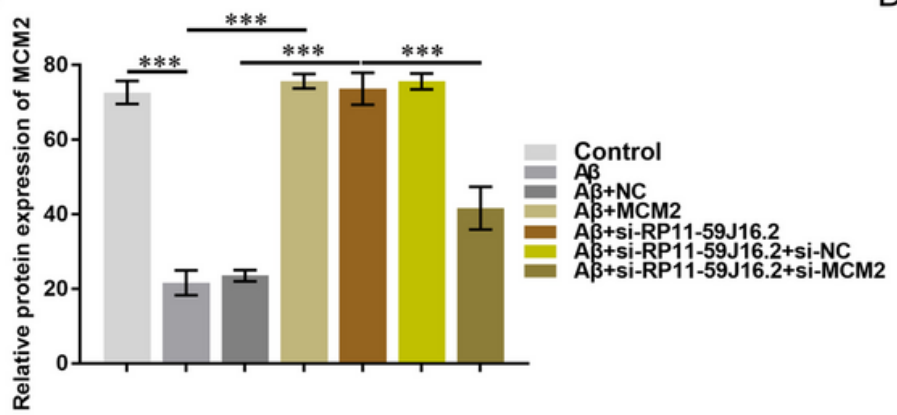

B

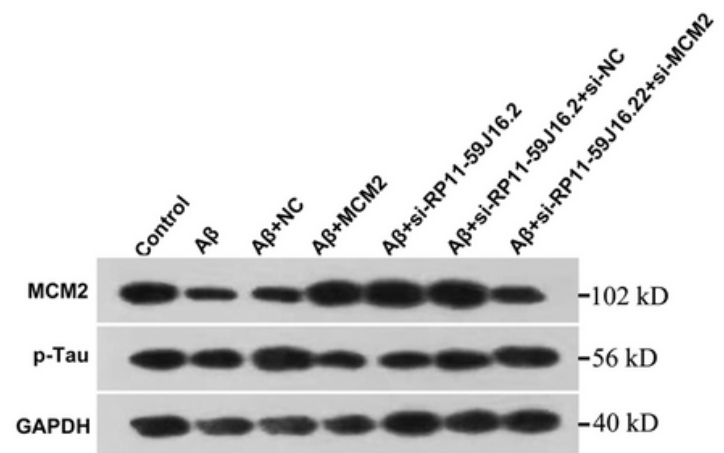

D

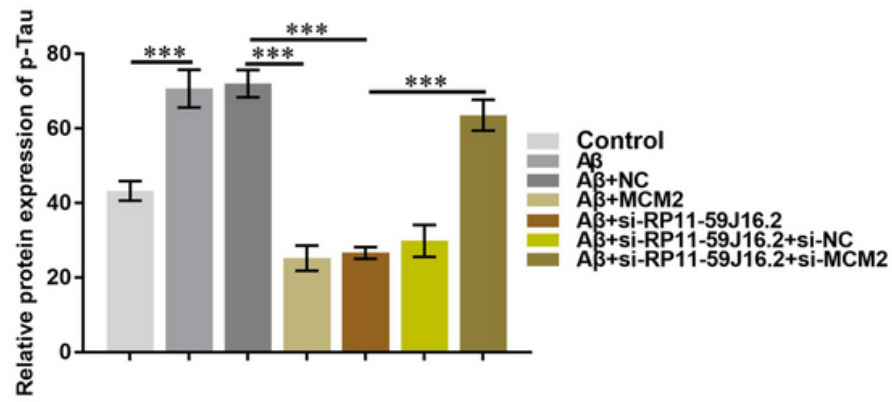

Figure 9

RP11-59J16.2 regulate $p$-Tau expression by inhibiting MCM2. (A) qRT-PCR was used to detect p-Tau expression in each group. (B) Western blot was used to detect $\mathrm{p}$-Tau and MCM2 expression in each group. p-Tau expression was significantly decreased after transfection with si-RP11-59J16.2 or MCM2. The expression of p-Tau increased significantly in si-RP11-59J16.2 + si-MCM2 transfection group compared with si-RP11-59J16.2 or MCM2 group. The expression of $\mathrm{p}$-Tau and MCM2 was negatively correlated. (C, D) Quantitative results of Western blot about the relative expression of MCM2 and p-Tau. The experiment was repeated three times in each group, ${ }^{\star \star \star} P<0.001$. 